\title{
Bringing the Concept of Drop-in Fuels into the Pulp and Paper Industry
}

\author{
Rayssa Pinto, Marcos Lúcio Corazza, and Luiz Pereira Ramos * \\ The pulp and paper sector is undertaking several initiatives to \\ decrease the carbon footprint of its industrial activities. To do so, \\ any emission must be offset by introducing efficient carbon fixation \\ strategies such as reforestation and the development of biobased \\ products and processes. The production of drop-in fuels may play \\ an important role in this scenario. Drop-in fuels provide a good way \\ to add value to otherwise underutilized process streams and \\ wastes, reducing greenhouse gas emissions, minimizing other \\ environmental impacts, and improving process sustainability.
}

Keywords: Renewable hydrocarbons; Biomass conversion; Drop-in fuels; Biorefinery

Contact information: Federal University of Paraná, Department of Chemical Engineering, Curitiba, PR, 81531-990, Brazil; *Corresponding author: luiz.ramos@ufpr.br

\section{The Problem}

Planet Earth calls for a reduction of the environmental impact of human economic activities. Among other evidence, the emission of greenhouse gases (GHGs), one of the most important indicators of climate change, has increased significantly in recent times. Every day, GHGs sourced from human activities build up in the atmosphere, where they cause catastrophic effects such as global warming, impairment of the planet's biodiversity, pollution of seas and oceans, desertification and/or loss of soil fertility, extreme weather events, displacement of animal populations, and a range of other impacts. Because most GHG emissions stay in the atmosphere for tens to hundreds of years after being released, their climate warming effects persist over a long time and can therefore affect both present and future generations (IPCC 2014). The main GHG components are carbon dioxide $\left(\mathrm{CO}_{2}\right)$, methane, hydrofluorocarbons, and nitrous oxide. Among these, $\mathrm{CO}_{2}$ contributes almost $60 \%$ of the GHG effect and is generated mainly from the burning of fossil fuels such as coal and oil (IEA 2019).

To reduce the consequences of environmental disasters that are afflicting the planet, human economic activities ought to become carbon neutral, a condition in which GHGs no longer accumulate in the atmosphere. However, climate scientists argue that we are already too late for carbon neutrality to be an effective solution, and that we must focus on carbonnegative strategies, a condition whereby more $\mathrm{CO}_{2}$ is captured from the atmosphere compared to the amount of $\mathrm{CO}_{2}$ emitted to the atmosphere.

\section{The Solution}

Biomass as an energy source directly contributes to the decarbonization of the atmosphere because its combustion emits less $\mathrm{CO}_{2}$ than fossil fuels while plant growth captures $\mathrm{CO}_{2}$ via photosynthesis. In addition, biofuels can be produced from the residues of forestry, agriculture, and agro-industries, adding value to coproducts that would be normally disposed of. For this reason, Brazil is privileged for its favorable climate and the ample availability of land for cultivation of energy crops. Two important national biofuel programs emerged in Brazil in the mid 70s. The Pró-álcool program encouraged the use of hydrated ethanol as neat fuel and anhydrous ethanol in blends to replace part of the national demand for gasoline. The Oveg program, which evolved to the National Program for 
Biodiesel Production and Use launched in early 2005, aimed to investigate vegetable oils and biodiesel (fatty acid alkyl esters) to replace part of the national demand for petrodiesel. Today, ethanol is widely used in flex fuel vehicles either as neat or E25 blends with gasoline, while biodiesel use follows a mandate currently at B13, with plans to increase the biodiesel content in diesel up to $20 \%$ (B20) by 2028. Both national programs were created in response to the world oil crisis in the mid 70s.

\section{The Technology Behind}

Renewable fuels can be produced for several applications, such as in the transportation sector to replace crude oil aviation fuels, gasoline, and diesel. Ideally, such biofuels are required to be functionally equivalent to those of petrochemical origin and fully compatible with the existing petroleum infrastructure, with the advantage of being fully sustainable. Also, in a transition to a biobased economy, drop-in fuels such as green diesel, biogasoline, and sustainable aviation fuels (SAF) can be progressively introduced in the energy matrix, starting with its use in blends and gradually evolving to their use as neat fuel. One can also envisaged the use of drop-in fuels as fuel additives to improve the emission profile of both conventional and sustainable fuels. Ethanol and biodiesel are liquid biofuels that are widely used in blends worldwide.

The technologies used to produce drop-in fuels can be classified into thermal (gasification, pyrolysis, and liquefaction), biochemical (fermentation alone and followed by alcohol oligomerization), and catalytic (hydrotreatment) processes (Kargbo et al. 2021). For all steps that requires hydrogenation, it is essential to ensure wide availability of green hydrogen $\left(\mathrm{H}_{2}\right)$ such as that obtained by alkaline electrolysis. However, this is a high-energy consumption process that must be based on renewable energy sources such as wind, solar, or hydroelectric power. For this and other reasons, other $\mathrm{H}_{2}$ sources such as blue $\mathrm{H}_{2}$ from petrochemistry will predominate in the short term.

Four main routes have been extensively investigated to produce hydrocarbons from renewable resources: hydrotreatment of vegetable or animal oils and fats, fermentation processes, alcohol oligomerization, and Fischer-Tropsch (FT) synthesis based on biobased syngas (EPE 2020). Although most studies carried out to date have been oriented to natural gas, there is an increasing understanding that biogas coming from anaerobic digestion should be reformed to biobased syngas for FT synthesis (Okeke and Mani 2017). Also, atmospheric and biobased $\mathrm{CO}_{2}$ may be reformed to syngas. While atmospheric $\mathrm{CO}_{2}$ would require capture (which may be advantageous for being carbon negative), biobased $\mathrm{CO}_{2}$ would arise from bioprocesses such as fermentation or from biogas refining technologies to produce biomethane (in this case, $\mathrm{CO}_{2}$ is recovered as the refining off-gas).

\section{The Opportunity}

Figure 1 describes some of the technological routes that would fit into this biorefinery concept. Bark, sawdust, unclassified chips, fiber rejects, black liquor, and other lignin streams can be converted to drop-in fuels by thermal processes, having bio-oil, biocrude, and syngas as process intermediates. Lignocellulosic materials can also be oriented to second-generation biofuels such as cellulosic ethanol, while $\mathrm{CO}_{2}$ emissions could be captured or concentrated to undergo reform followed by FT synthesis. $\mathrm{CO}_{2}$ hydrogenation to methanol followed by oligomerization to drop-in fuels is also a possibility, with the latter being also applicable to second-generation oxygenated biofuels such as ethanol and butanol. Another opportunity is the hydrotreatment of tall oil to produce drop-in fuels such as hydrotreated vegetable oils (HVO) and hydroprocessed esters and fatty acids (HEFA), with some of the $\mathrm{H}_{2}$ demand supplied by gasification. This and other initiatives not only improve the destination of unused or underutilized process streams, but also diversify the product portfolio of the pulp and paper sector. Such 
strategies can help to reduce its dependance on fossil fuels while improving its carbon footprint, developing new products, and adding value to the entire production chain. For instance, the carbon footprint of crude tall oil derivatives is as much as $90 \%$ lower than its fossil counterparts (Aryan and Kraft 2020).

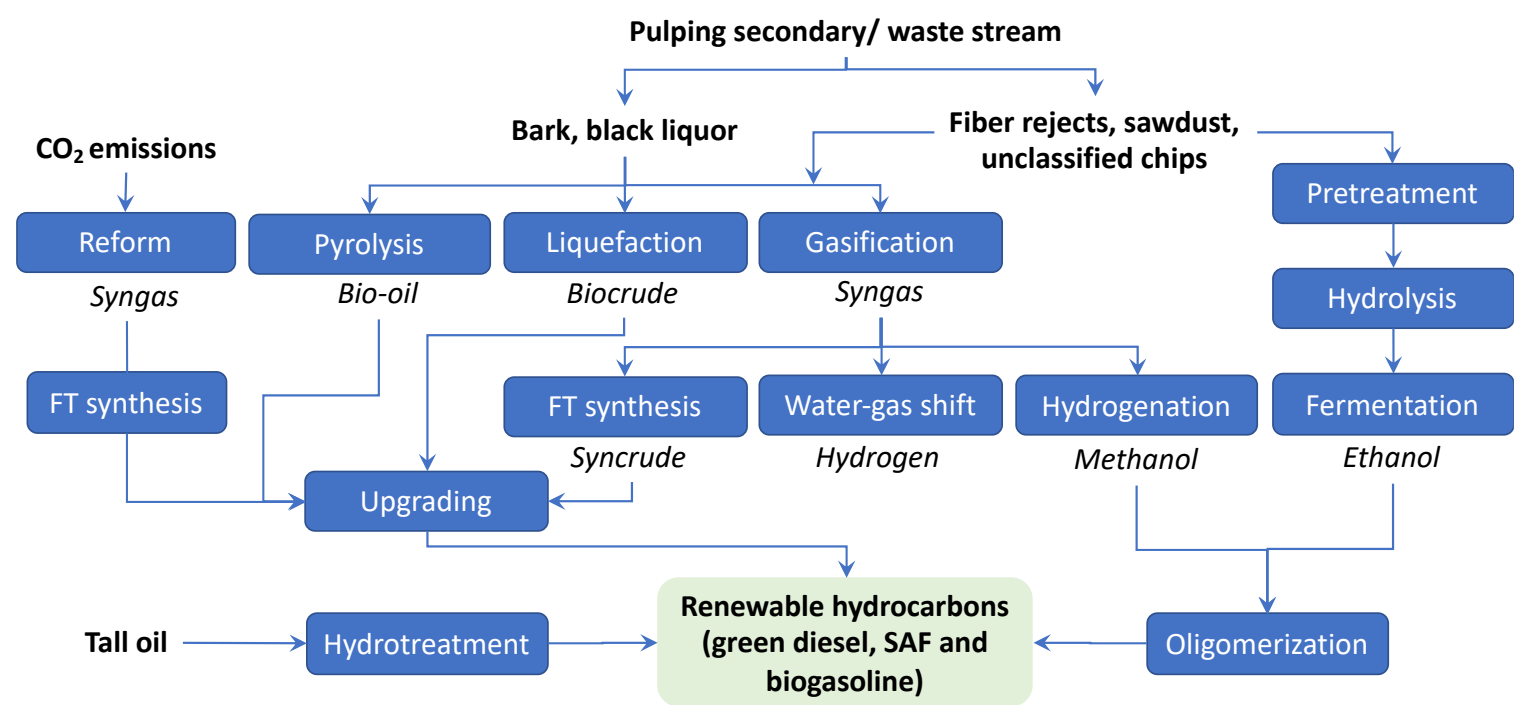

Fig. 1. Emerging technologies to produce drop-in biofuels in the pulp and paper sector

\section{The Future}

Researchers, politicians, companies, funding agencies, and government offices are increasing their awareness about the urgent need to preserve our natural resources and reduce the accumulation of environmental liabilities in our planet. The search for sustainability still requires research and development, but this must be seen as an opportunity for innovation rather than an obstacle. In this context, biofuels can bring a tremendous contribution to modern society, particularly in the form of drop-in fuels. While some solutions are not yet economically viable in large scale, others are reaching commercial scale, and the goal of combining economic development with environmental protection is gradually becoming a reality in process design, optimization, and operation for the benefit of generations to come.

\section{Referenced Cited}

Aryan, V., and Kraft, A. (2020). "The crude tall oil value chain: Global availability and the influence of regional energy policies," Journal of Cleaner Production 280(1), article no. 124616.

EPE - Empresa de Pesquisa Energética. Combustíveis renováveis para uso em motores do ciclo diesel. Nota Técnica DPG-SDB Nº1, 2020.

IEA - International Energy Agency. Drop in Biofuels: The key role of co-processing will play in its production. IEA Bioenergy: Task 39, 2019.

IPCC - Intergovernmental Panel on Climate Change. Summary for Policymakers Climate Change 2014 Mitigation of Climate Change. Working Group III Contribution to the Fifth Assessment Report of the Intergovernmental Panel on Climate Change. Pag. 9. Cambridge University Press, Cambridge, UK, 2014.

Kargbo, H., Harris, J. S., and Phan, A. N. (2021). "Drop-in" fuel production from biomass: Critical review on techno-economic feasibility and sustainability," Renewable and Sustainable Energy Reviews, 135, article no. 110168.

Okeke, I. J., and Mani, S. (2017). "Techno-economic assessment of biogas to liquid fuels conversion technology via Fischer-Tropsch synthesis," Biofuels, Bioproducts and Biorefining, 11(3), 472-487. 